\title{
Gender Equality in the Post-2015 Development Agenda: Lessons from the MDGs
}

\author{
Gita Sen
}

\begin{abstract}
This article addresses some central issues for the Post-2015 Development Agenda from a Southern perspective on gender equality and women's human rights. To answer this question, it first examines what lessons can be learned from the decade or so of implementation of the MDGs. The article focuses on two 'meso' challenges: breaking down issue silos, and integration/participation. It argues that progress towards gender equality will depend on whether the larger development framework addresses central issues such as the growing inequality, informalisation and precariousness of work and incomes that have gone hand in hand with the globalisation of the past three decades. Within a framework that tackles head on the causes and consequences of rising global and national inequality, progress on women's rights requires recognition that gender inequality is pervasive across multiple and intersecting issues. Effectively addressing women's needs and rights requires the building of bridges across policy silos through the integration of issues and participation by women.
\end{abstract}

\section{Introduction}

Global debates about the Post-2015 Development Agenda are in high gear at the present time. Multiple, overlapping and sometimes potentially contradictory processes are at work with many stakeholders - governments, multilateral, bilateral and independent organisations, private actors including corporations and other major groups, and a wide range of civil society organisations heavily engaged in these processes. With so much activity, debate and discussion, as well as new reports and interventions appearing in quick succession, it is easy to lose sight of the wood for the trees. This article asks what that wood might look like from a Southern perspective on gender equality and women's human rights. In order to answer this question, we first examine what lessons can be learned from the decade or so of implementation of the Millennium Development Goals (MDGs). In the interests of brevity, the article will not address the question of specific gender goals, targets and indicators even though it recognises that the devil may well be in these details (UN Women 2013).

It focuses instead on two 'meso' challenges: breaking down issue silos, and integration/ participation. It argues that addressing these is especially important to achieving gender equality and fulfilling women's human rights.

An important concern is that the MDGs never really tackled the larger macroeconomic and development framework within which policies or programmes for gender equality are located, or how conducive that framework is likely to be. There is a growing worry that something similar may happen with the Post-2015 Development Agenda (DAWN 2013). From the perspective of gender equality, this lacuna can have a number of consequences. The challenge of informal labour markets provides a useful illustration. The phenomenon of the working poor has been growing in the last three decades of globalisation not only in developing but also in high-income countries, and has been exacerbated in the aftermath of the financial crisis of 2008. Standing (2011) has called such workers the 'precariat' - workers who work more than full-time (by organised worker standards) but whose livelihoods are precarious and vulnerable.

In many developing countries, over 80 per cent of women workers belong to this category. The 
traditional definition of social security, based on a male breadwinner model, has especially failed women workers as it has ignored the labour and resource requirements of the 'care' economy in the household and structural gender power inequalities. Traditional social protection includes at best maternity benefits (usually only for organised workers unless the state steps in), and does not include childcare or access to clean water, sanitation or fuel that are all critical ingredients of the 'care' economy for which women are held responsible.

Gendered access to resources and divisions of work and responsibilities determine who is most vulnerable within households, why, and at what points in the lifecycle. For instance, this can affect girls' access to food and health care in societies with son-preference, and education in societies that have not yet gone through a demographic transition (so that girls are expected to care for younger siblings while their mothers work) or where secondary schools are distant, do not have women teachers, or clean toilets. It also contributes to women's excessive work burdens, absence of rest or leisure, and inability to obtain the skills and technologies that can enhance their earnings. Widowhood (divorce, desertion) is often a time of great hardship for women - in addition to threats of violence and sexual predation, they are also at risk from attempts to deprive them of inherited assets from their deceased husbands. Women tend to be much poorer than men at older ages.

It is increasingly recognised that social protection has to mitigate such longstanding gendered and other vulnerabilities and deprivation as well as the consequences of growing informalisation of labour. The need for an agreed social protection floor as part of the Post-2015 Development Agenda is very great, especially given the large numbers of people involved and the volatility and unpredictability of multiple risks. Rights-focused approaches can ground such a floor in principles and mechanisms of justiciability and accountability that can provide the best protection for the chronically poor and vulnerable 'precariat'.

\section{What have we learned from the MDGs?}

Few would deny that the MDGs successfully focused the global policy spotlight on some key development issues in the past decade. At the same time, almost from the beginning, there has been criticism and challenge of a number of perceived errors of omission and commission. A number of key actors involved in the assessment of the MDGs and the design of the Post-2015 Development Agenda have voiced some or all of these criticisms and more (Fukuda-Parr 2012; Vandemoortele 2012). They argue that the MDGs diluted the ambition and overarching vision of the Millennium Declaration. In doing so, they 'dumbed down' the richer and more complete goals and targets of the UN conferences of the 1990s, whose approaches were grounded in the lived realities of people's needs in different countries and regions. A major gap was in the area of sexual and reproductive health and rights. The global consensus goal of universal access to reproductive health by 2015 that was reached at the UN International Conference on Population and Development (ICPD) in 1994 fell through the cracks until it was recovered much later as Target 5b.

Furthermore, the MDGs missed the interconnected character of the risks and vulnerabilities faced by the very people they were focused on. Risks and vulnerabilities on the basis of economic, social and political inequalities and environmental and demographic factors interact systematically to make risks not only more complex, but also requiring a multifocal approach putting people at the centre, but this was almost completely neglected. The consequence was the creation of a set of goals that became silos in themselves with critical inter-linkages and synergies remaining untapped; this was especially true for how weakly the MDGs addressed the core problem of gender power relations and inequalities.

If this was not enough, there was also no clarity or agreement on the 'hows' - processes, approaches and methods - as distinct from the 'whats' of goals and targets. While the diversity of national and local contexts has of course to be recognised, it is also necessary to have available benchmarks, good practices and implementation challenges. The absence of an effective focus on methods and processes was due in part to the fact that the determination of goals, targets and indicators became in the main a technocratic exercise conducted, as some have said, in windowless rooms in UN buildings, and without 


\section{Box 1 Has progress towards MDG targets reached women?}

\section{Goal 1: Eradicate Extreme Poverty and Hunger}

It is well known that much of the global reduction of more than 800 million people living in extreme poverty from 1990 to 2008 was due to reduction in poverty rates in two countries India and China. Despite this reduction, women continue to be more likely to live in poverty than men. Women in sub-Saharan Africa are over-represented in poor households, both because they are less likely to have paid work, and because when they do have paid work their average pay is lower than for men. Women's lack of productive resources and their 'time poverty' are important reasons for their relatively higher poverty rates. In the Asia-Pacific region, countries other than India and China have not performed so strongly. It must also be noted that there has been considerable debate about the actual extent of poverty reduction in India, and despite the reduction in the poverty ratio, the actual numbers of poor people have increased, with a concentration in the rural areas where over 65 per cent of the population still live.

The proportion of workers in vulnerable employment is slowly shrinking, but women remain the most affected by far in nearly all regions. The proportion of women workers in the Asian region who are vulnerable (working on their own account or as unpaid family workers) ranged from 41 per cent in West and Central Asia to over 80 per cent in South Asia. This has significant implications both for poverty and hunger, as well as the need for a social protection floor.

\section{Goal 2: Achieve Universal Primary Education}

There has been significant progress across all developing regions in reducing gender gaps in primary school attendance. The increase in poor girls' attendance has contributed to a 59 per cent reduction in the gap between the richest and poorest girls. However, large differences in attendance persist between rich and poor in all regions, and the quality of education remains poor. These differences are smaller in the Asia-Pacific region and primary education appears to have been a rising tide lifting all boats.

\section{Goal 3: Promote Gender Equality and Empower Women}

The situation is less positive for secondary school attendance with much smaller improvements overall, and a persistent gender gap. These results are also true for the Asia-Pacific region.

Unequal pay for comparable work, sometimes even lower statutory minimum wages, and poor working conditions including violation of women's sexual and reproductive rights (lack of toilets, rest breaks, maternity benefits, and childcare facilities), sexual harassment and violence against women are rife among informal women workers in both the organised and unorganised sectors of enterprises. Even allowing for differences in education and training, women's wages are lower than for men. Globally, women occupy only 25 per cent of senior management positions and, in 2008/09 were on average paid 23 per cent less than men.

Women's representation in parliaments has improved only slowly, and is under 25 per cent overall, including even in 'developed regions'. In Southern, Southeastern, and East Asia the range is between 18 and 20 per cent.

adequate public debate or transparency especially with civil society. Consequently, short shrift was given to the human rights-focused approaches that greater and more genuine participation and engagement of the people for whom the MDGs were intended would likely have prioritised.
Perhaps, most crucially, incorporation of the macroeconomic policy environment (global and national) that generated key policy barriers and enablers for the achievement of the MDGs (such as fiscal, monetary, trade and investment policies) was quite inadequate. While MDG 8 on developing a global partnership for development 


\section{Goal 4: Reduce Child Mortality}

Recent analysis of gender gaps in under-five mortality in countries where data are available shows that the gap favouring boys narrowed in Southern Asia between 1990 and 2011. But differential child mortality rates reflect the consequences of gender bias and daughter aversion in some countries.

\section{Goal 5: Improve Maternal Health}

Age at first marriage is rising, but women in poor and rural areas continue to marry young, and richer women are more likely to receive needed maternity care. Early and forced marriage of girls and weak access to maternal care are especially (but not exclusively) problems in Southern Asia.

\section{Goal 6: Combat HIV/AIDS, Malaria and other Diseases}

More than 60 per cent of the roughly one million HIV infections among young people aged 15-24, are among girls and women. This means that each year, nearly 600,000 young women are newly infected with HIV. Of the total 2.7 million new HIV infections in 2010, close to one million were among young people aged 15-24, and this does not take account of infections among younger adolescent girls below the age of 15 for whom data are often not collected, and who are among the most vulnerable. Their vulnerability, like that of their older sisters, is due to the pernicious interaction of biological factors and gender power relations. Although the HIV/AIDS epidemic appears to be more under control in Asia than in sub-Saharan Africa, the Pacific sub-region is seeing an upward spike in new infections.

\section{Goal 7: Ensure Environmental Sustainability}

The MDG target of halving the proportion of people without sustainable access to safe drinking water has apparently been achieved five years ahead of schedule. But, as of 2010, nearly 800 million people still lacked access to improved water sources. Most of them were poor people in rural areas. Where water is not available, it is overwhelmingly the task of women and girls to collect and haul water, sometimes over long distances. Official data suggest that the problem is more serious in sub-Saharan Africa than in Asia; however the reliability of these data is open to question for some countries as they often use the most inclusive measures of access, which are not necessarily a good reflection of the realities on the ground.

\section{Goal 8: Develop a Global Partnership for Development}

The total amount of bilateral sector-allocable aid increased every year between 2008 and 2010. But while the proportion of this aid devoted to gender equality objectives increased in 2009, it stalled in 2010. Generally, the feeling among women's organisations is that funding for civil society organisations that advocate for women's rights has shrunk significantly, and this poses a serious challenge to their ability to hold major stakeholders to account (AWID 2010).

Source UN Women (2012).

included important elements on trade and debt, this was the MDG that had the least in-built accountability for implementation. Without clarity about the broader development framework, it was perhaps not surprising that the MDGs fell into policy 'silos' with especial damage to the needs of gender equality.

\section{Moving beyond silos - focusing on women}

Policy silos have some obvious advantages. They are relatively simple to design, and easy to execute by line ministries or departments. The MDGs tended from the start to become silos because a number of them were defined in terms of specific issues such as education, maternal 
mortality, child mortality, etc. that were congruent with the ambit of line ministries (and specialised UN agencies). This made them easier to monitor and evaluate through a limited set of indicators for the achievement of targets and goals.

Convenient as these policy silos may have been, their very simplicity may have been misleading and overdone. For instance, while MDG 3 on gender equality and women's empowerment was broad, it was given a single target ('eliminate gender disparity in primary and secondary education, preferably by 2005 , and in all levels of education no later than 2015'), enshrining thereby the dubious belief that education can be a proxy for all aspects of gender equality. The indicators for this target were somewhat broader and included women's political representation and non-agricultural wage employment, but these were only indicators, not targets. The relationship between these indicators and the target itself was quite unclear.

There has been considerable critique of this by women's organisations and a few UN agencies that challenged this approach as inadequate, and called for recognition of the fact that gender equality cuts across all the MDGs and is essential to their fulfillment (WHO 2003; DAWN 2012). In its recent Gender Chart (UN Women 2012), UN Women provides important evidence confirming this. These data and other reliable evidence point to the extent of the impact of gender inequality on all of the MDGs (see Box 1).

It is clear from the contents of Box 1 that the cross-cutting and multidimensional nature of gender power and inequality cannot be effectively addressed through a single target on education alone as the MDGs attempted to do. The roots of deprivation and inequality lie in power relations that cut across multiple aspects of people's lives and are not specific to particular issues such as education or health or hunger. Rather, they appear to be specific to particular groups of persons such as women and girls, and also groups disadvantaged or subordinated on other grounds. Furthermore, these multiple sources of power inequality often intersect and reinforce each other. For instance, it is well known that, in India, the intersecting oppressions of economic inequality, caste and gender place poor dalit women at the bottom of the social ordering, such that they are disadvantaged in relation to all of the MDGs, not just one or two. Addressing their disadvantages as persons rather than simply tackling them within issue silos could be a promising approach for the Post-2015 Development Agenda.

How then can the Post-2015 Development Agenda address the need for simplicity and parsimony in goals/targets/indicators without losing the valuable insights provided by a multidimensional approach to gender equality that is based on human rights? One way forward could be to retain the goals as broad and issuefocused, for example the goal for gender equality could remain as stated by MDG 3: to 'Promote Gender Equality and Empower Women'. But the target derived from the goal could be in terms of specific group/s of people who are disadvantaged, subordinate, at risk or vulnerable. Many advantages can flow from combining an issue-focused goal with people-focused targets. By focusing directly on the needs of people in an integrated way, it can become possible to: (1) move beyond issue silos; (2) simultaneously address people's needs directly while having an impact on multiple dimensions of inequality (other things remaining the same); (3) retain the simplicity of having clear goals that are easy to understand while also tackling the question of processes, participation and accountability; (4) guard against policies focusing only on low-hanging fruit in terms of population groups that are less at risk and easier to handle in terms of social subordination; and (5) acknowledge and address the interacting risks and vulnerabilities that people face.

\section{Addressing the 'hows' - integration and participation}

An examination of the evidence on the MDGs shows that, across different goals, certain groups of people recur in terms of the observed achievement gaps for many different targets. These include poor women, young people, migrants, dalits, ethnic, religious or racial minorities, and indigenous people, inter alia. The groups most at risk may vary across regions and countries. The decision about whom to target should be based on clear criteria for indicators determined globally in accordance with human rights standards and human development achievements. Subject to such uniform global criteria, the choice of groups can be made at the national level in a transparent and participatory manner. 
Setting targets in terms of the development and wellbeing of chosen groups implies that the needs of group members can be addressed holistically to take advantage of synergies across issues and to prevent degeneration into silos. Thus the development needs of poor rural women in a particular region can include rights to land, livelihoods, housing, childcare, health (including sexual and reproductive health services), literacy/education, employment, freedom from violence, political participation/representation, voice and agency. Addressing these needs holistically requires tackling five dimensions:

- Legal empowerment, including enabling legislation;

- Political participation and voice;

- Economic resources (including, inter alia, assets, livelihoods, work and incomes);

- Human development (health, education, water, sanitation, fuel, housing, childcare);

- Social protection to prevent, mitigate and protect against risks and vulnerabilities.

New institutional arrangements in an integrated mode will be required in order to ensure holistic treatment that can cut across line ministries and departments. But such institutions will only be as effective as the resources (financial and human) with which they are set up, and the level, placement and status that they are given (Kabeer and Subrahmanian 1999). One example of an attempt towards integration is the recently constituted National Mission for Empowerment of Women (NMEW), set up in 2010 by the Indian government. Its mission statement says: 'The Mission aims at strengthening processes that promote holistic development of women, gender equality and gender justice through inter-sectoral convergence of programmes impacting women, forging synergy amongst various stakeholders and creating an enabling environment conducive to social change' (NMEW n.d.). It is as yet too early to tell whether the NMEW will have any impact and how much, or whether its aim of holistic treatment and synergy will be matched by financial and human resources or political clout. A weakness is that the NMEW has been placed within the line ministry for women, thereby reducing its autonomy and also possibly its status.

Another critical element of the 'hows' is participation and accountability. Defining targets in terms of people makes it logical to involve them in determining what should be done and how it should be done to meet the goal. A major criticism of the MDGs was that the design and implementation of targets and indicators was too much of a technocratic exercise. Shifting towards a stronger affirmation of human rights including basic freedoms of self-determination and autonomy needs to be a core part of the Post2015 Development Agenda. Central to this will be how the agenda itself is set, and how much of a role people will have in shaping it.

Involving people directly in determining what will be done on their behalf will tend to make the choices more grounded and robust. It will also make programme implementation more effective and efficient. For women, this means not only their presence and participation but their voice and leadership. The role of political space for women's leadership cannot be over-emphasised.

An example is India's experience with quotas in village councils mandated by an amendment to the Constitution of India in 1993 that has generated much interest over the years on whether the entry of around a million women into the councils would catalyse social change. Early evidence pointed to mixed results - greater voice and agency for women but also many instances where women were simply 'dummies' or proxies for male family members. New evidence points, however, to more solid and sustained change. A study in the Birbhum district of West Bengal found that, in villages with seat quotas for women in the previous two elections, the proportion of women elected went up significantly even if the village no longer had a quota. Male villagers' evaluation of women leaders' effectiveness went up significantly. Most importantly, the gender gap in aspirations closed for adolescents as did the gap in their educational attainment (J-PAL 2012). Another study in Sangli district in the state of Maharashtra found similar results; with a learning/experience lag of about 3-4 years, elected women leaders performed at least as well as men in the provision of services, and their presence empowered other women to participate in democratic processes (Sathe et al. 2013).

This illustrates the importance not only of positive discrimination in levelling the gender playing field but also that it needs time in order to be able to break through long-encrusted patterns of subordination and inequality. 


\section{Conclusion}

This article has argued that the Post-2015

Development Agenda has some crucial lessons to learn from the experience of the MDGs.

Progress towards gender equality will depend on whether the larger development framework addresses central issues such as the growing inequality, informalisation and precariousness of work and incomes that have gone hand in hand with the globalisation of the past three decades.

\section{References}

AWID (Association for Women's Rights in Development ) (2010) Where is the Money for Women's Rights? Select 2009 Research Highlights and Trends, www.awid.org (accessed 18 June 2013)

DAWN (Development Alternatives with Women for a New Era) (2013) From People's Rights to Corporate Privilege: A South Feminist Critique of the HLP Report on the Post 2015 Development Agenda, www.dawnnet.org/advocacy-appeals.php? signon $=306 \& i d=306$ ? $($ accessed 18 June 2013)

DAWN (Development Alternatives with Women for a New Era) (2012) Breaking Through the Development Silos: Sexual and Reproductive Health \& Rights, MDGs and Gender Equity - Experiences from Mexico, India and Nigeria, e-book, http://issuu.com/dawnfeminist/docs/breakings ilos (accessed 18 June 2013)

Fukuda-Parr, S. (2012) Recapturing the Narrative of International Development, Gender and

Development Programme Paper 18, Geneva: United Nations Research Institute for Social Development (UNRISD)

J-PAL (Abdul Latif Jameel Poverty Action Lab) (2012) Raising Female Leaders, J-PAL Policy Briefcase, April, www.povertyactionlab.org/ publication/raising-female-leaders? (accessed 18 June 2013)

Kabeer, N. and Subrahmanian, R. (1999) Institutions, Relations and Outcomes, New Delhi: Kali for Women

NMEW (National Mission for Empowerment of Women) (n.d.) Mission Statement, www.nmew.gov.in/ (accessed 18 June 2013)
Within a framework that tackles head on the causes and consequences of rising global and national inequality, progress on women's rights requires recognition that gender inequality is pervasive across multiple and intersecting issues. Effectively addressing women's needs and rights requires the building of bridges across policy silos through integration of issues and participation by women.

Sathe, D.; Klasen, S.; Priebe, J.; Biniwal M. (2013) 'Can the Female Sarpanch Deliver? Evidence from Maharashtra', Economic and Political Weekly XLVIII.11, 16 March

Standing, G. (2011) The Precariat - The New Dangerous Class, London: Bloomsbury Academic

UN Women (2013) A Stand-Alone Goal on Achieving Gender Equality, Women's Rights and Women's Empowerment: Imperatives and Key Components in the Context of the Post-2015 Framework and Sustainable Development Goals, www.un-ngls.org/ .../UN_Women_Note_on_Gender_Equality_ Goal-3.pd (accessed 18 Jüne 2013)

UN Women (2012) The Millennium Development Goals Report. Gender Chart 2012, www.unwomen.org/ wp-content/uploads/2012/.../MDG-Genderweb.pdf (accessed 18 June 2013)

Vandemoortele, J. (2012) 'Advancing the Global Development Agenda Post-2015: Some Thoughts, Ideas and Practical Suggestions', background paper prepared for the Experts Group Meeting to Support the Advancement of the Post-2015 UN Development Agenda, New York, 27-29 February

WHO (2003) En-gendering the Millennium Development Goals (MDGs) on Health, WHO, Department of Gender and Women's Health, www.who.int/gender/mainstreaming/en/ MDG.pdf? (accessed 18 June 2013) 